\title{
A Função da "Personalidade do Estado" na Elaboração Penal do Fascismo Italiano: laesae maiestas e tecnicismo-jurídico no Código Rocco (1930)
}

\author{
The Function Of "State Personality" In The Criminal Elaboration Of Italian \\ Fascism: laesa maiestas and the technical-legal school in the Rocco Code (1930)
}

\author{
Arno Dal Ri Jr. ${ }^{1}$ \\ Kristal Moreira Gouveia ${ }^{1}$ \\ ${ }^{1}$ Universidade Federal de Santa Catarina (UFSC), Florianópolis, SC, Brasil
}

\begin{abstract}
Resumo: O presente artigo discute a função da personalidade jurídica atribuída ao Estado no Código Penal Italiano de 1930 para a instituição de categorias autoritárias e totalizantes. Para isso, buscou-se inicialmente localizar a importância do Código no itinerário fascista de imposição de poder. Foram analisadas quais funções do direito penal foram flexibilizadas, ignoradas ou atribuídas. Por meio da ressignificação da expressão laesa maiestas, focou-se na relação entre a nova figura do Estado no contexto do Código Penal e o deslocamento de tutela de reconhecimento de bens jurídicos posterior, em especial no que se refere à virada punitivista, que coloca o indivíduo como alvo e como possível ameaça e não mais como sujeito da tutela jurídica. Por fim, foram analisados os institutos maculados de forma mais visível por essa característica e sua reminiscência na atual legislação penal italiana..
\end{abstract}

Palavras-chave: História do Direito Penal. Tecnicismo Jurídico. Legislação Criminal Italiana.
Abstract: Italian Penal Code of 1930 to the institution of authoritarian and totalizing categories. To this end, it initially seeks to locate the importance of the Code in the fascist itinerary of power imposition. We analyze which functions of criminal law were flexibilized, ignored or attributed. Through the resignification of the expression "laesa maiestas", we focus the relationship between the new figure of the State in the context of the Penal Code and the displacement of guardianship of recognition of subsequent legal assets, in particular approaching the punitivist turn, that puts the individual as a target and possible threat and no longer as a subject of legal guardianship. Finally, we analyze the tainted institutes of the actual Criminal Code, those in which where there are in a more visibly way reminiscences of this characteristc.

Keywords: Criminal Law History. TechnicalLegal School. Italian Criminal Law.

Recebido em: 21/01/2019

Revisado em: 25/02/2019

Aprovado em: 11/03/2019 


\section{A Codificação Penal como Instrumento do Itinerário Fascista Italiano}

A edificação do regime fascista apoiou-se em uma série de movimentos de ordem política, social e jurídica na tentativa de tornar totalizante o domínio sobre os setores da vida dos indivíduos, utilizando-se das instituições como caixas de ressonância dos objetivos de um centro de poder total e unificador. São movimentos que, segundo Emilio Gentile ${ }^{1}$, caracterizariam o fascismo italiano imposto por Benito Mussolini a partir 1924 como uma modalidade peculiar de totalitarismo.

A produção de um sistema de legislação penal que traduzisse a ideologia política do regime fascista italiano, portanto, fazia parte desse itinerário $^{2}$, sendo o ordenamento jurídico um reflexo dos princípios que

\footnotetext{
${ }^{1}$ Em que pese a divergência doutrinária sobre a atribuição do termo "totalitarismo" ao regime fascista italiano (muito embora este tenha sido o único dos regimes nacionalistas europeus contemporâneos que autodenominou-se totalitário explicitamente, adota-se aqui o conceito de Emilio Gentile (2008), que visualizando características religiosas no regime, o compreende como um sistema de "cesarismo totalitário", que define como: “[...] a charismatic dictatorship integrated in an institutionalized regime structure, based on the single party and on mass organization and mobilization, in continuous construction to make it consistent with the myth of the totalitarian State, consciously adopted as reference model for the organization of the political system, and actually operating as fundamental code of beliefs and behaviors imposed on botth the individual and the masses". Vide, também, sobre a ciência jurídica italiana no fascismo italiano COSTA, Pietro. Lo "Stato totalitario": Un campo semantico nella giuspubblicistica italiana. in Quaderni fiorentini per la storia del pensiero giuridico moderno, 28 (1999), p. 61 ss.

${ }^{2}$ É imprescindível compreender o itinerário das mudanças ocorridas na legislação penal para a compreensão de seu papel no regime. Sobre isso "I lavori preparatori dei condici italiani - uma bibliografia" (2013): "L'avvento del Fascismo si innestò sulle prospettive di riforma. Con 1. 24 dicembre 1925, n. $2260[\rightarrow$ CP 49, 1], il ministro Alfredo Rocco ottenne per il governo della facoltà di modificare i codici penale e di procedura penale. A tal fine, fu nominata una commissione ministeriale, presieduta da Giovanni Appiani, dalla quale nacque un gruppo ristretto, presieduto dallo stesso ministro. Un primo articolato data alla fine del $1926[\rightarrow$ CP 43]. Nei primi mesi del 1927 si lavorò al secondo Libro $[\rightarrow \mathrm{CP} 43,2]$ e al terzo «Delle contravvenzioni in ispecie» $[\rightarrow \mathrm{CP} 44,3]$. Nel giugno del 1927 l'articolato [ $\rightarrow$ CP 44, 1] venne ancora rivisto e nell'ottobre successivo esso si concretizzò nel progetto presentato alla commissione ministeriale (senza relazione) $[\rightarrow$ CP 45]. Discusso ed elaborato da questa commissione [ $\rightarrow$ CP 49, 4.1-4.4] e dagli operatori
} 
alicerçam uma dada ordem política. Essa passagem do itinerário fascista materializou-se por meio da emanação de um conjunto normativo, que em sua ramificação penal foi composto por um novo código de normas substantivas, um código de normas adjetivas e normas extravagantes voltadas à segurança do Estado e à reforma do ordenamento penitenciário 3 .

Entre essas espécies legislativas, recorta-se substancialmente, para análise no presente trabalho, o Código Penal. Duas são os motivos que conduzem a essa delimitação. O primeiro é o fato de que, no seu texto original, o código penal de 1930 pode ser visto como uma autêntica expressão do contexto político no qual foi emanado. Essa era a visão de Alfredo Rocco ${ }^{4}$, então Ministro da Justiça, cujo nome batizou o referido código. Em sua obra "La trasformazione dello Stato" (1927), Rocco compreende a lei penal como o ramo do Direito que melhor define os propósitos do Estado, visão que por si só demonstra ser possível compreender os traços pretendidos pelo regime por meio das escolhas legislativas penais delineadas no Código.

O segundo motivo é o fato de que o Código Penal de 1930 acabou por sobreviver às sequenciais revogações das demais legislações supramencionadas a partir da derrocada do regime, estando atualmente em vigor, mesmo que tenha sofrido diversas reformulações, em especial que

e cultori del diritto [ $\rightarrow$ CP 49, 3.1-3.4, CP 50], il Progetto definitivo [ $\rightarrow$ CP 49, 5.1.-5.3] fu indirizzato alla commissione parlamentare nell'ottobre 1929; questa si divise in tre sottocommissioni e lo prese in esame $[\rightarrow \mathrm{CP} 49,6]$. Quindi, dopo un'ultima revisione tecnica, il testo del nuovo Codice penale fu presentato dalla Relazione del Guardasigilli $[\rightarrow$ CP 49, 7] e pubblicato con R.D. 19 ott. 1930, n. 1398 [ $\rightarrow$ CP 53]: entrò in vigore il I lug. 1931, quando erano state emanate le disposizioni di coordinamento e transitorie [ $\rightarrow$ CP 54]".

${ }^{3}$ Ao conjunto dessas legislações se atribuía o nome "Código Rocco", passando a referirse somente ao Código Penal de 1930 apenas a partir das reformas de 1974 e 1989 que aboliram os dois demais (DAL RI Jr., 2006, p. 227).

${ }^{4} \mathrm{O}$ significado da legislação penal no contexto de afirmação do Fascismo pode ser visualizado claramente no discurso de apresentação do esboço final do Codice por Alfredo Rocco (1930), ao dizer que "dentre os mais distintos monumentos dessa legislação está a reforma legislativa penal, uma manifestação impositiva do poder do gênio legal italiano, que a nova consciência nacional criada pela guerra e pelo Fascismo libertou de todos os rastros de ideias estrangeiras e tradições, direcionando-a em direção a conceitos que são ainda mais originalmente e genuinamente italianos." (tradução nossa). 
excluem os institutos mais visivelmente autoritários. Ainda assim, é o código em vigor, fato este atribuído a uma série de razões tanto de cunho político como jurídico ${ }^{5}$. Não obstante as reformas que retiraram e modificaram institutos fascistas, dadas suas indissociáveis raízes o código é considerado por muitos como uma "lei maculada".

Recortada a análise legislativa ao Código Penal de 1930, o Codice Rocco, delimitamos o estudo sobre seus institutos autoritários que materializam uma das características da legislação fascista: a atribuição de uma personalidade ao Estado. Traço marcante das escolhas legislativas feitas na nova conjuntura ordenatória foi a centralização do poder ao Estado, com o deslocamento da proteção dos indivíduos, característico do liberalismo, à proteção deste, em tal nível que se atribui uma personalidade estatal própria a ser resguardada de forma prioritária à dos utentes.

Thiago Pires Marques indica essa materialização, segundo ele presente em diversos artigos, como um resgate da ideia do Antigo Regime de laesa maiestas que personifica um traço importante do regime autoritário fascista: a centralização estrutural da proteção jurídica ao Estado, a escolha de seus elementos como bens jurídicos tutelados e a definição das condutas puníveis: Estes elementos são representações das escolhas cons-

\footnotetext{
${ }^{5}$ A curiosa permanência do Código Rocco em vigência não se deve, conforme explica Stephen Skinner (2011) a uma ausência de projetos para substituí-lo. O autor justifica o fato de nenhum das dezenas de projetos apresentados nas décadas do pós-guerra ter sido implementado devido a uma série de fatores, tais como falta de vontade política, falhas nas propostas, fraqueza das coalisões governamentais; Porém atribui significativa importância às crises enfrentadas na Itália em relação ao combate ao terrorismo e ao crime organizado, momentos políticos em que utilizar-se de disposições autoritárias do Código - porém sob outra ótica - foi utilitário. A esse respeito, explica que "in these difficult circumstances it has sometimes been convenient for the authorities to have recourse to some of the stringent, authoritarian, provisions that were still available in the Rocco Code".

"O termo "lei maculada" é tradução livre para a expressão "tainted law", trazida por Stephen Skinner (2011, p. 431) para qualificar o Código atual, por ser derivado/estar conectado com um regime de violência como o fascismo e naturalmente com o contexto e objetivos do regime, que originaram este código. Nessa perspectiva, mesmo com as alterações, permanecem elementos "derivados" que tornam a lei prejudicada desde a origem, maculada, tanto por conta da "violência fundacional" como pela capacidade contaminatória de sua influência corruptiva (SKINNER, 2011, p. 440).
} 
cientes feitas em detrimento da proteção individual, vista somente como instrumental à vontade do Estado (e muitas vezes oposta à essa última, caso em que a vontade estatal deveria definitivamente prevalecer) ${ }^{7}$.

Alguns dos referidos artigos nos quais essas categorias emergem permanecem vigentes (embora com parciais modificações), conforme será abordado na sequência.

A localização da função do Código no itinerário fascista, neste âmbito, se reveste de um particular significado. Por um lado, à função do Código como categoria elementar da ordem política e, por outro, o seu enquadramento na dinâmica entre Estado e cidadão, por meio da abordagem aplicada ao princípio da legalidade.

A importância central do Código Penal para concretização do ideário fascista é inegável, de acordo inclusive com elementos já introdutoriamente apresentados ${ }^{8}$. Alfredo Rocco, portanto, entendia a lei penal como

\footnotetext{
${ }^{7}$ Rocco (1930) opõe-se explicitamente à filosofia contratualista e consequentemente à noção de que o poder estatal deriva das vontades dos indivíduos, que o delegam de acordo com uma dada limitação por elas imposta. Essas concepções, que ele chama de "ultra-individualistas" são diametralmente opostas à ideologia do fascismo. Como o próprio autor coloca, em seu discurso de apresentação do esboço final do projeto: "Para concepções ultra-individualistas do direito de punir, que constitui, invés, mais em uma negação do que uma afirmação desse direito, considerado como uma Graciosa concessão feita pelos indivíduos para o Estado de uma forma que é sempre mutável e revogável e tem sempre como limitação a intransponível barreira do direito natural dos indivíduos à Liberdade, ao menos na extensão de que essse não foi cedido, a filosofia penal jurídica do Fascismo é tenaz e logicamente oposta".

${ }^{8}$ A estratégia de inovar legislativamente no campo penal, parte do itinerário fascista totalizante supramencionado e o caráter autoritário e repressivo das disposições legais torna indissociável a figura do código do contexto de afirmação fascista no qual se localiza. A esse respeito, já em 1933, Mario Bulhões Pedreira explanava que "[...] não é possível isolar o novo código penal italiano, de factura fascista, da obra de renovação legislativa na Italia, modelada à feição deste pensamento superior que attribue ao Estado a função dirigente, coordenadora de todas as organizações individuaes, disciplinando a vida científica, econômica, religiosa e artística do paiz". Como se pode ver, nunca houve uma dissimulação em relação aos propósitos do Codice. Ao contrário, o forte ímpeto nacionalista e impositor vinha explicitamente manifesta no Fascismo Italiano e verbalizava-se através de seus apoiadores encontrando no Código um fiel retrato do que espírito nacionalista que buscava-se imbuir nos utentes.
} 
expressão máxima do direito de punir, atribuindo importância maior a essa legislação dentre todas as integrantes do sistema jurídico, por entender o referido direito de punir como um dos maiores atributos da soberania, e ainda, considerada pelos ancestrais como uma das maiores manifestações de imperium 9 .

Uma consideração que merece destaque sobre o regime fascista e já foi bastante discutida na historiografia do direito é a escolha pela não derrogação do princípio da legalidade, contrariamente ao que ocorreu nos regimes autoritários da Alemanha Nazista e da União Soviética. Essa decisão provém da utilização do princípio da legalidade como forma de exercício de poder pelo Estado Fascista ${ }^{10}$. Diversa de uma limitadora da atuação estatal, a lei, por meio do viés adotado do princípio da legalidade, passou a ser utilizada como expressão da vontade coercitiva estatal.

A decisão de não abolir o princípio da legalidade, ao menos não de maneira completa, não obstante seu uso providencial, é um dos pontos que para alguns autores situa o Código Rocco em uma área anterior à entrega completa ao totalitarismo ${ }^{11}$. Talvez seja justamente por tal motivo

${ }^{9}$ Ainda no discurso de apresentação do esboço final do Código Penal, Alfredo Rocco centraliza a importância da referida legislação nos seguintes termos: "Nella nuova legislazione la riforma penale eccelle non solo per la sua intrinseca grandiosità, ma altresi per la importanza, indubbiamente superiore, che essa ha, in confronto di ogni altra riforma legislativa. La potestà di punire è infatti uno dei massimi attributi della Sovranità, tanto che i nostri anticht ravvisavano in essa una delle più essenziali manifestazioni dell'imperium, e la assimilavano, nella sua più completa capacità d'esercizio, al potere di disporre della forza armata dello Stato (jus gladii). E veramente tale potestà è anch'essa una forma di difesa statuale, é anch'essa una guerra contro attività nemiche, che devono essere debellate nell'interesse dello Stato e della società".

${ }^{10}$ Sobre esse tema, Diego Nunes (2016, p. 157): "O fascismo via no princípio de legalidade uma forma de enaltecimento da autoridade do Estado por meio da obediência à legislação. $\mathrm{O}$ argumento já foi muito discutido no âmbito da história do direito penal para compreender a opção italiana de não se valer da derrogação do princípio de legalidade penal, ao contrário da União Soviética e da Alemanha nazista. Aqui se deseja tratar do distanciamento da legalidade como forma de aplicar a lei - rígida como afirmação da autoridade do Estado - da legalidade no procedimento legislativo - flexível para dar um sentido autoritário aos mecanismos da democracia liberal".

${ }^{11}$ Esse ponto perfunctoriamente contraditório gera um debate sobre a localização do fascismo entre aspectos liberais, totalitários e seus diferentes níveis. Emblemática desses 
que, em meio as estratégias que tentavam a perversão do princípio da legalidade, algumas categorias liberais conseguiram sobreviver, por meio dos poucos elementos que permaneceram desse princípio ${ }^{12}$.

No entanto, essas categorias devem ser analisadas à luz da utilização dada a estes institutos. A sobrevivência por si só do princípio da legalidade não significa que a há uma continuidade clara ou ainda coerente com os princípios que sustentam o sistema liberal, muito embora haja a continuidade de certos institutos. A sobrevivência desse princípio, portanto, não pode ser vista como um argumento que afaste do Código Rocco o caráter autoritário e fascista ${ }^{13}$.

Os institutos inseridos no Código para materializar a referida vontade estatal, porém, dão azo à uma próxima discussão, que é o enquadramento dessa legislação no debate entre as escolas penais, a ser explanado no próximo tópico.

embates, a concepção de Fiandaca, por exemplo, contempla o Código como fruto de um processo de continuidade do velho sistema liberal, justificando esse pensamento justamente na não renegação do princípio liberal (DAL RI Jr., 2006, p. 228-229).

12 Sobre o tema, Tiago Pires Marques (2011) defende que o princípio da legalidade juntamente ao da imputabilidade são elementos que denotam que o modelo de justiça criminal italiano não era completamente totalitário, não tendo havido um abandono completo desses paradigmas liberais em favor do chamado "sistema de defesa social", cujo rumo natural seria uma codificação reconhecidamente desigual, como foi o caso alemão com o nazismo.

${ }^{13}$ Isso se deve à função dada ao princípio da legalidade no regime fascista e sua oposição à função liberal utilizada no regime precedente. Sobre esse tema Musumeci (2017): "Contrary to appearances, during the Fascist era the 'glorified' principle of legal certainty did not perform the same functions that it would have done in a democratic legal system. The principle provides that one cannot be subjected to penal sanctions unless these are previously provided for by law. During the Fascist regime, however, laws were issued without wide, democratic parliamentary debate, but instead as the will of a single party, the Fascist Party, which since the beginning of the dictatorship had trampled on every kind of political opposition. This then was the 'law' - legal, but not legitimate - to which the principle of legality referred". 


\section{O Código Rocco no Debate entre Escolas Penais}

No ambiente historiográfico que se dedica a análise do impacto do fascismo no direito penal, até os dias de hoje permanece a questão acerca do enquadramento a ser dado ao Código Rocco entre Positivismo e a Escola Clássica, assim como a sua possível transposição por meio da adoção de uma terceira escola ${ }^{14 / 15}$.

Esse enquadramento guarda sentido diretamente com o reconhecimento de um caráter eminentemente fascista (ou não) nos institutos do Código.

A tentativa de perpassar os debates e superar ambas as escolas é um fato de clara percepção devido aos discursos que acompanham a edição e publicação do código ${ }^{16}$. É emblemático, neste sentido, o discurso de Arturo Rocco irmão do ministro Alfredo Rocco, ainda em 1910, na Universidade de Sassari, intitulado "Il problema e il metodo della scienza del diritto penale", quando declara a necessidade de livrar-se do legado da

\footnotetext{
${ }^{14}$ Sobre essa afirmação, Daniel Pick (1989, p. 147): "Rocco's code represented the triumph of penological ecleticism which amalgamated elements of classicism and positivism. It market the rise of a so-called 'Third School', which sought to avoid the metaphysical philosophy of the classical approach, and the biological or sociological determinism of the positivists. The 'technico-juridical' school, as it has also been termed, made a new appeal to clarity of language in the framing of law. It sought to establish a 'pure' field of rights and penaltires. Heavily utilitarian in scope (crime was definied as that which destroys or diminishes a 'good', or which sacrifices a uman 'interest', it sought to produce new rigorous definitions of such terms as 'motive' and 'will' via a kind of jurisprudential logical positivism".

${ }^{15}$ Não se trata aqui da denominação de terza scuola de Impallomeni e Alimena.

${ }^{16}$ Os institutos do Código devem ser lidos e interpretados à luz dos discursos que o acompanharam, para compreensão de que princípios essa lei criminal buscava viabilizar. Sobre a importância dos discursos (incluindo tanto de Arturo Rocco, 1910, como o de Alfredo Rocco, quando da publicação do último rascunho do Código), Skinner (2011, p. 450): "Read in this way, the significance of the discourse concept as an interpretative tool is particularly apparent, as it underlines the interaction of contextual and ideological forces in Rocco's representation of criminal law. In other words, the context, construction and connections of Rocco's declarations about criminal law show how he sought to draw on these various levels of significance to create a particular, Fascist conception of penality anchored in a Fascist perception of the world".
} 
Escola Positiva estabelecida por Lombroso, culpado de "manchar" a "pureza" da lei criminal devido à interferência de outras disciplinas ${ }^{17}$.

Grande parte do movimento ao entorno da publicação do Código baseava-se também na ideia de que a Escola Clássica deveria ser afastada, devido seus princípios e preceitos serem demasiadamente abstratos e teológicos, assim como de que a Escola Positiva trazia uma "contaminação" de outras disciplinas à ciência jurídica. Conforme enunciava Rocco, a partir dessa ocasião ${ }^{18}$, a concepção da nova lei penal seria a de garantir um direito "puro", sem a contaminação positivista de outras ciências e afastado de conceitos secularizados e dogmáticos da escola Clássica. Essas influências, ao longo do tempo, tinham tornado o direito penal, para Rocco, um direito penal sem direito ${ }^{19}$.

A intenção era que o Código Rocco fosse pautado total e completamente na técnica jurídica. Razão pela qual seu estilo pode ser enquadrado

\footnotetext{
${ }^{17} \mathrm{O}$ referido discurso de Arturo Rocco, tal como sua obra "Il problema e il metodo della scienza del diritto penale" (1910) apontam para o que foi chamado de criação de uma base legal para a implementação da escola técnica jurídica como base para o futuro código e ainda como "manifesto de uma nova abordagem legal técnica para a lei criminal" (MUSUMECI, 2017), no entanto, a discussão sobre a influência das duas escolas no texto do código (em especial à influência positivista no instituto da defesa social, que garantia proteção ao Estado ao mesmo tempo que resgatava noções de periculosidade e de antecipação de condutas) continua tão presente a ponto de em 2010 terem sido tema de debate quando do centenário da referida palestra de Rocco. Sobre a importância dessa questão, Musumeci (2017) ressalta: "Far from being a mere academic disquisition, unravelling the contribution made by Arturo Rocco might shed light on the true nature of the Rocco Code and its relationship to Italian criminal law doctrines, since Arturo Rocco was the president of the committee of experts appointed by the Minister of Justice to draw up the preliminary draft of the penal code and supervise the final project".

${ }^{18}$ Sobre a distância entre as concepções presentes nos escritos de Rocco de 1910 para o fascismo, vide SBRICCOLI, Mario. Le mani nella pasta e gli occhi al cielo. La penalistica italiana negli anni del fascismo. in Quaderni fiorentini per la storia del pensiero giuridico moderno, 28 (1999), p. 817 ss.

${ }^{19} \mathrm{Na}$ referida palestra de 1910 , Rocco enuncia que a escola a resguardar a lei penal deve ser a escola do tecnicismo jurídico: "È giunto il momento di tenersi fermi, religiosamente e scrupolosamente attaccati allo studio del diritto positivo vigente. La scienza giuridica va circoscritta ad un sistema di principi di diritto...ad una conoscenza scientifica della disciplina giuridica dei delitti e delle pene [...]È questo l'indirizzo tecnico-giuridico, il solo indirizzo possibile in una scienza appunto giuridica".
} 
em uma terceira escola, conhecida entre os penalistas como a escola "técnico-jurídica", mas o fato é que o discurso não necessariamente traduz o texto. É possível, portanto, constatar a existência de institutos das duas correntes repudiadas no âmbito do próprio código. Tal fenômeno permite, deste modo, compreender como, a partir dessas categorias, quais elementos delineiam e possibilitam a apresentação de institutos que criaram forma e força por meio do código, como a própria personalização do Estado.

Mesmo sendo ainda bastante individualista - e, em muitos pontos, até liberal -, o direcionamento do Código Rocco ao tecnicismo jurídico apresenta, entre seus objetivos, a necessidade de adequar os institutos jurídicos à utilidade desejada pela legislação criminal, que é a proteção do Estado com a retirada do foco da questão penal do indivíduo. Para isso, uma estrutura pautada unicamente na técnica jurídica é utilitária a medida que afasta concepções que remetem a outros tipos de criminalidade ou a elementos que vinculem a proteção penal ao sujeito. Trata-se da "virada tecnicista" 20 , que trouxe consigo como apoiadores grandes estudiosos do penal $^{21}$.

${ }^{20}$ É impossível fazer referência à adoção do tecnicismo jurídico e não mencionar o fato de que sob o manto de uma suposta imparcialidade técnica, muitos juristas aderiram intelectualmente ao regime fascista. Conforme desenvolve Sbriccoli (2011, p. 478), a virada tecnicista é "benéfica por um lado, porque contribui para sanear a ciência penal, liberando-a dos detritos da invasão positivista (terríveis sociologismos, autoritarismo áspero, repressivismo antiliberal), mas também precursores de um empobrecimento cultural que, a longo, prazo, os penalistas pagarão com um penoso isolamento.". Sobre a neutralidade dos juristas, Musumeci $(2017$, p. 5) exalta a ilusão de um isolamento da lei como garantia de neutralidade, processo que na verdade esconde uma vontade política consciente: "the technical legal approach advocated by Arturo Rocco was nothing more than a moderately sweetened variety of legal formalism that enhanced the isolation of law from other spheres, entirely separating it from reality, in order to serve the alleged neutrality of the jurist. In that neutrality, under the cloak of 'technical' analysis, is hidden the inevit able subordination of the law to political power, as actually occurred under the Fascist regime".

${ }^{21}$ É muito importante sublinhar que um dos grandes motores da força do regime foi justamente o apoio declarado e fundamentações confeccionadas pela classe jurista, apoiados nessa mesma noção de direito por direito, direito neutro, por ser meramente técnico. Essa máscara isentava-os da responsabilidade de lidar com o significado dos dispositivos que agora apoiavam. Conforme aborda Sbriccoli (2011, p. 480): "Nada pequena, em tudo isso, como escrevi em outro lugar, fora a responsabilidade dos 
A questão da presença de elementos de proveniência do positivismo lombrosiano no Código Rocco não é unânime mesmo atualmente. A constatação que emerge como geradora deste postulado advém do fato de que algumas categorias aprofundadas pela Escola Positiva, tais como a "periculosidade", o "sujeito delinquente" e "a defesa do Estado" constituíam um discurso frequente na legislação criminal de 1930, remetendo a categorias trazidas pela Escola Positiva. Com isso se mantém o foco da punição no sujeito e não no ato em si. Além disso, o instituto que prevê as medidas de segurança ${ }^{22}$, assim como o caráter de antecipação de condutas de acordo com elementos previamente presentes, são visualizados como heranças da Escola Positiva, pois por meio da verificação de circunstâncias prévias, previam medidas antecedentes um crime. Trata-se aqui da polêmica figura da "medida de segurança", um dos institutos que traduz uma guinada pouco liberal que vinha se formando desde o início do século XX, assim como a erosão de direitos e garantias individuais dos indivíduos e a reversão do foco de proteção jurídica.

O que se discute, porém, é até que ponto estes institutos à primeira vista "herdados da Escola Positiva" foram distorcidos. O Código Rocco é pautado em uma noção fundamental de forte punibilidade pelo Estado em relação ao sujeito, sob a motivação de garantir uma suposta proteção ao "sujeito Estatal" contra toda e qualquer ameaça que venha do indivíduo. Para a concretude dessa dada proteção, muito foi flexibilizado ou mesmo aniquilado no tocante a direitos e garantias fundamentais dos indivíduos.

A punição, deste modo, toma contornos mais violentos e fortes. Distancia-se dos escritos da Escola Positiva, que usava essas categorias como forma para prever um perfil criminoso. O Código Rocco foi além, fazendo da punição um poder ilimitado e natural derivado da figura forte e protagonista do Estado, atribuída como consequência de sua própria

juristas. Imersos sem resíduos numa cultura autoritária que lhes tinha apagado qualquer preocupação pelos direitos."

22 Sobre a presença das medidas de segurança no Código Rocco, uma especial influência é visualizada na redação do Código Brasileiro contemporâneo. A esse respeito, ver SONTAG, Ricardo. 'Código criminológico'? Ciência jurídica e codificação penal no Brasil (1888-1899). 1. ed. Rio de Janeiro: Revan, 2014. v. 1. 368p. 
natureza ${ }^{23}$ e com um instrumental amplo de aplicação contra ameaças e possíveis ameaças. Subsiste uma cisão, portanto, à título de finalidade e princípio fundamental no tocante ao objetivo com o qual os institutos eram usados.

A questão que emerge, então, é até que ponto as características derivadas da ideia geral de periculosidade trazida pelo positivismo foram distorcidas e reinterpretadas somente para servir de fundamento ${ }^{24}$ e legitimação para essa nova formatação de Estado. É possível, de fato reconhecer que existe uma ligação entre as categorias da Escola Positiva e alguns institutos inseridos no Código, mas também percebe-se que a forma de emprego desses elementos essenciais é manejada de forma diferente daquela que faziam uso os seguidores de Lombrosi, Ferri e Garofalo ${ }^{25}$.

O que se isola nesse debate, para desenvolvimento do tópico final, é uma noção específica, que possui raízes conceituais na escola positiva,

${ }^{23}$ Esse conceito deriva da própria figura de Estado que o fascismo edificou, como será visto a seguir. No entanto, por hora, tenha-se em mente a imagem de um ente que "[...] é apresentado como um organismo ao mesmo tempo econômico, social, jurídico, ético e religioso. Como organismo econômico-político, por exemplo, o Estado não constitui mais a soma aritmética dos indivíduos que dele fazem parte, mas sim o resultado, a síntese dos sujeitos, das categorias e das classes que o constituem. Uma entidade que tem vida própria, necessidades e fins próprios aos quais estão subordinados os interesses individuais" (DAL RI Jr., 2006, p. 230-231). Assim, o forte poder ilimitado do Estado, que reflete na pena não é um instrumento mediador da sociedade - como no Positivismo, por exemplo, e sim uma consequência da própria visão fascista de Estado - seria de sua natureza possuir este poder.

${ }^{24}$ Esse argumento é enfrentado por Musumeci (2017) que defende que embora o Código Rocco de 1930 pareça ser um "estranho híbrido entre teorias clássica e positiva", em especial por conta do uso dos conceitos positivistas de "periculosidade" e medidas de segurança, essa aparência é apenas um disfarce, uma vez que o Código não aderiu verdadeiramente aos princípios Lombrosianos e tão somente utilizou elementos positivas instrumentalmente (e ao avesso das finalidades originais dadas a estes pelo positivismo), para fundamentar os institutos repressivos do fascismo. Como se pode ver, este não é ainda um tema pacífico na historiografia.

${ }_{25}$ Para maior aprofundamento da questão, ver: M. ROMANO, Il codice Rocco e i lineamenti di una riforma del diritto penale politico; G. FIANDACA, Il codice Rocco e la continuità istituzionale in materia penale, Dibattito su 'Il codice Rocco cinquant'anni dopo", in La questione criminale, 1981, I; E.R. ZAFFARONI, Alla ricerca del nemico: da Satana al diritto penale, cit., p. 757-78. 
ou seja, o conceito de "defesa social do Estado". Utilizado pelo Positivis$\mathrm{mo}^{26}$, tal conceito é considerado o percussor (em que pese as distorções comentadas, e a nova semântica adotada) de uma nova noção que surgia na legislação fascista, a de personalidade do Estado. É este conceito que nos leva à discussão final e principal: Como a personalidade do Estado é apresentada na legislação criminal de Alfredo Rocco e quais as consequências desses contornos nos institutos autoritários.

\section{Laesa Maiestas: as consequências autoritárias da "personali- dade do Estado" no Código Penal italiano de Alfredo Rocco}

A ideia de defesa social, conceito fundamental da Escola Positiva, na legislação criminal de 1930 é remodelada de acordo com um deslocamento do papel do sujeito da proteção da lei penal, assim como de sua finalidade. O Estado, visto na ótica do regime fascista, não é mais um administrador de interesses individuais e coletivos e sim uma entidade com evidentes trações antropomórficos, que inclui todos (mas não é a soma deles) e possui uma relevância e importância maior do que a de todos ao mesmo tempo.

Nessa concepção, que em alguns aspectos faz recordar aquelas utilizadas pelas correntes organicistas germânicas do final do século XIX, o Estado passa a ser considerado a potência e o verdadeiro sujeito de direitos e para isso deve exercer sua força e ser protegido por meio da lei. Essa mudança de foco torna claro como foi delineada a categoria de segurança do Estado no regime fascista, sendo a esta adicionada uma nova noção, adotada e reinterpretada do direito público, chamada de "personalidade do estado".

\footnotetext{
${ }^{26}$ Sobre o tema, Tiago Pires (2011, p. 79), "The above justifications for the reform of penal and police institutons carried out in the early 1920s show that criminal positivism and the language of social defence provided the leading politicians of the fascist regime with a new semantics of social disorder. Concepts such as the 'born criminal', the 'habitual offender', the 'instinctive delinquent' and the potentially dangerous juvenile delinguqnt were not unanimously accepted among penal profissionals".
} 
A existência de uma personalidade do Estado transforma a dinâmica com os indivíduos, modificando-o de mediador para sujeito a ser protegido. Como consequência toda a legislação passar a ter mais uma função: deixa de ser somente uma ponte entre relações Estado e Indivíduos, passando a lei criminal a ser garantidora da proteção do Estado, inclusive contra os indivíduos No bojo das medidas inovadoras que buscaram garantir essa proteção e sedimentar a essa desproporção de força estão os dispositivos que possibilitam "antever" comportamentos potencialmente perigosos dos indivíduos, legitimando ao Estado o uso da violência mesmo antes da execução de uma ação considerada perigosa.

Essa perspectiva apresenta como consequência a configuração do poder de punir como um diritto di conservazione e di difesa proprio dello Stato, nascente con lo Stato medesimo ${ }^{27}$. A imagem do Estado como "o órgão vivo do direito" ${ }^{28}$, atribui à lei a função de reprimir e prevenir qualquer ameaça ${ }^{29}$ ou ato que atente contra os elementos de sua própria personalidade. Essa função garante tanto a instituição de medidas preven-

${ }^{27}$ Estes termos foram usados pelo Rocco nos "Lavori preparatori del codice penale e del codice di procedura penale. Vol VII. Roma: Mantellate, 1930, p.12”.

${ }^{28}$ Conforme Corso Bovio (1931, p. 21): "Lo Stato è l'organo vivente del diritto. Esso deve preservarsi dalla sua distruzione e da quella degli organi fondamentli della sua sovranità, e deve pertanto antivenire gli sforzi dell'attività criminosa che sotto qualunque forma tendano a violarne l'autorità. La legge deve porgere allo Stato i mezzi efficienti e concreti per combattere gli sforzi dei nemici dell'ordine sociale, determinando con rigorosa precisione la nozione giuridica del delitto di Stato".

${ }^{29}$ É elemento extensivamente presente nos atos preparatórios do Código a discussão sobre a periculosidade do sujeito, e os perigos que podem acometer o Estado. Este termo aparece mais de 100 vezes no tomo VII dos "Lavori preparatori del codice penale". Esse é o fundamento para o sistema punitivo do duplo binário e para a adoção de métodos preventivos e repressivos em concomitância. Em dada passagem, discute-se: "La pericolosità criminale non è qualcosa di diverso dalla pericolosità sociale; ne è una specie; ha la stessa sua natura; ed è quindi ovvio che non possano essere considerate antagonistiche le attività dirette a combattere le due forme di pericolosità. La obiezione che possa, l'attività ordinaria di sicurezza, avere maggiore flessibilità d'iniziative e di movimenti, «li quella che sia consentita al giudice, potrebbe avere una qualche consistenza, se il Progetto avesse aderito all'indirizzo di taluni giuristi fautori della giurisdizionalizzazione delle misure di sicurezza, e, in secondo luogo, se l'ordinamento delle misure di sicurezza non lasciasse i più larghi margini alla comune attività di polizia. Ma né l'una né l'altra di tali ipotesi risponde al sistema adottato dall'attuale Progetto.”. 
tivas como as medidas de segurança, como a vinculação de penas mais rigorosas para as ações contra o Estado.

Passa a ser determinante, portanto, o papel do Código em substituir a antiga ideia de "segurança do Estado", proveniente da noção de "defesa social do Estado", pela ideia de "personalidade do Estado". Desse modo, por meio da operação acima descrita, o Estado vem inserido como categoria operacional central do instrumento punitivo. As consequências desembocam em categorias específicas que vão desde a estrutura do próprio Código, à atribuição de penas mais severas, incluindo a prisão perpétua e a pena de morte, cujo retorno à legislação marca de forma determinante o caráter autoritário do Código e, como já mencionado, a instituição das medidas de segurança e de caráter preventivo com base na periculosidade ${ }^{30}$.

O progressivo foco direcionado aos delitos contra a personalidade do Estado é o elemento que define o Código Rocco e justifica sua escolha pelo endurecimento das sanções à todas as ações que pudessem sugerir ou associar-se com os tipos previstos (ou ameaças). Essa escolha está presente desde a estrutura do Código. Seu título I do Livro II prevê a seguinte divisão interna: cinco capítulos que são respectivamente: delitos contra a personalidade internacional do Estado (artigos 241 a 275); Delitos contra a personalidade interna do Estado (artigos 276 a 293); Delitos contra os direitos políticos do cidadão (art. 294); Delitos contra o Estado estrangeiro, seus comandantes e representantes (artigos 295 a 300); E por fim disposições gerais e comuns aos capítulos precedentes (artigos 301 a 313). Desse modo, a elevação da personalidade do Estado para o bem

\footnotetext{
${ }^{30}$ Essa questão é confrontada por Tiago Pires (2011), que demonstra o deslocamento à figura de "personalidade do Estado" e sua consequência em três vertentes específicas do novo Código, conforme: "Aside from the hierarchy of values mentioned above, this expressive function of the penal code was rendered clear though the concept of "state personality", which undoubtedly offered a stronger representation of the state than the replaced formula of 'state security' ever did. This is all the more evident as crimes falling within this category entailed particularly harsh penalties, chief amongst them being capital punishment. Traditionally, the category of crimes against the state covered three distinct fields: the external dimension of state sovereignty, that is, its international authority and national autonomy; the state's internal sovereignty, or the concrete institutional organization of political power; and the basic rights of citizens in their relationship with the state".
} 
jurídico ${ }^{31}$ e sua proteção por meio de tantas previsões penais que incluem momentos anteriores e posteriores a uma suposta ofensa à personalidade estatal representam uma característica central do Código Rocco, em alguns momentos inovadora, garantindo ao Estado um poder de repressão mais forte e intenso, além de legitimar a interferência total em vários campos da vida individual e coletiva.

Esses delitos que visam resguardar a segurança do Estado ${ }^{32}$, colocam todos os que podem vir a opor-se a ele na situação de inimigos, criando uma relação de desproporção e oposição que aparentemente resgataria elementos da noção de laesa maiestas ${ }^{33}$. Essa expressão, conforme Giuffrida (2012), o insere em uma "moltitudine di modelli che avevano come denominatore comune quello di punire ogni comportamento di dissenso o disobbedienza al soverano".

A noção de "personalità dello Stato"34 denota atribuição a um sujeito, ou seja, uma conotação que resgata a noção subjetiva de majestade

${ }^{31}$ Sobre o tema, Antonio Giuffrida (2012): “L'elevazione della 'personalità dello Stato' a bene giuridico protetto rappresenta una delle innovazioni del codice Rocco che riflette maggiormente l'ideologia autoritaria del regime fascista. Invero, nell'ambito dei codici preunitari, vi erano numerose fattispecie criminose riconducibili al concetto di 'delitto politico' identificate, per lo più, con l'espressione crimen laesae maiestatis [...]".

${ }^{32}$ Essa segurança está vinculada à noção de Estado do qual se imbuiu o Código, conforme Corse Bovio (1931, p. 22), "[...] non si può parlare dei delitti contro la sicurezza delo Stato, senza tener presente il carattere che la funzione dello Stato assume nella civiltà moderna per fissare giuridicamente i vincoli ed obblighi del cittadino nel confronti dello Stato. Lo Stato è la suprema autorità, anche spirituale".

33 A expressão laesa maiestas, cuja tradição literal é "majestade injuriada" (injured majesty). Tiago Pires (2011) explica que essa expressão, que era utilizada na tradição civilista do Antigo Regime, foi posteriormente substituída por "segurança do Estado". No entanto, com a adoção já explanada do novo conceito de "personalidade do Estado", seus pressupostos voltam a se manifestar. Conforme explica o autor (p. 97), "the notion of state personality adopted by the fascist lawmaker restored the subjective connotation of laesa maiestas. Through this process of juridical personalization of the State, the criminal law as a right of mediation between individuals was then turned into a right of the State to self-defence reminiscent of the Old Regime".

${ }^{34}$ personalità s. f. [dal lat. tardo personalîtas -atis, der. di personalis «personale1»]. - 1 . non com. L'esser personale, tipico, caratteristico di una singola persona: la personalita di un'opinione, di un'idea; personalita del diritto o della legge. 
do termo laesa maiestas, devolvendo ao Estado uma centralidade antes vista no Antigo Regime. A aplicação desse conceito é fruto da centralidade dada ao Estado nesse novo contexto, no aparato de proteção a ele destinado e especialmente à extensão da centralidade que receberam no Código as categorias sancionadoras de "ofensas contra a personalidade do Estado" $"$.

Sobre a manifestação objetiva dessa noção nos dispositivos do Código, alguns pontos específicos são significativos. Da estrutura acima mencionada, perceba-se que apenas um artigo foi dedicado à proteção dos direitos políticos do cidadão, o artigo $294^{36}$. Atenção redobrada para os delitos que trazem a antecipação da punibilidade, em especial "delitti di attentato, associativi" e "di opinione", mostrando a arbitrariedade à liberdade de pensamento, muito embora não se tratem de figuras inovadoras na legislação.

Direitos de liberdade também são feridos por meio da punição exacerbada prevista para os "delitti associativi", que são conforme o código punidos "per ciò solo" 37 , ou seja, prescindem de um ato terrorista ou que

\footnotetext{
${ }^{35}$ Ainda sobre o tema, Tiago Pires Marques (2011) desenvolve: "According to this line of thought, breaking with the liberal tradition of the nineteenth century, the notion of 'state personality' adopted by the fascist lawmaker restored the subjetctive connotation of laesa maiestas. Through this process of juridical personalization of the state, the criminal law as a right of mediation between individuals was then turned into a right of the state to selfdefance reminiscente of the Old Regime. The most evident imprint of this concept on the Rocco $\backslash$ Code was the extension and the centrality given to the category of 'offenses agains the personalit of the state' (the link between the death penalty with the attempts agains the state personailty depicted the fundamental asymmetry of forces between the state and single individiduals.; lastly the rebaptized category, developed in all its potential in the jurisdicion of the Special Tribunal for the Defence of the State".

${ }^{36} \mathrm{O}$ fato foi apontado na proposta di legge de iniciativa dos deputados Turco, Artini, Baldassare, Barbanti, Bechis, Mucci, Prodani, Rizzeto e Segoni, para a retirada do art. 265, apresentada já em 17 de novembro de 2015: "Si riconosce invece solo un minimo spazio alla tutela dei diritti politici del cittadino: c'è solo un articolo, l'articolo 294 del codice penale, che con una formulazione piuttosto ampia persegue l'impedimento anche solo parziale dell'esercizio di un diritto politico se commesso con l'uso di violenza, minaccia o inganno".

37 Sobre o tema, Sereni (2012), "Nell'impostazione del 1930, d'altra parte, i delitti associativi del titolo I del codice dovevano caratterizzarsi per la finalità illecita
} 
atentem contra o Estado posterior, sendo clara manifestação autoritária de impedimento de reunião, devido a um suposto risco de futuro ato criminoso.

$\mathrm{O}$ caráter antecipatório se manifesta também no delito previsto o art. 266, de "istigazione e vilipendio". A instigação de militar a desobedecer à lei é um delito cuja consumação dá-se na planificação, ou seja, prescinde da obtenção de sucesso em convencer o suposto militar a desobedecer a lei. Ao passo que na legislação penal a instigação comum (art. 302) se consumava com a realização do ato posterior.

Outros artigos emblemáticos dos elementos aqui expostos são os artigos 336 e 337, que versam sobre a resistência à ação policial de forma incondicional, tratando da impossibilidade de desobediência por meio da força, sem uma especificação das situações excludentes desse tipo de resistência; Os artigos 268 e 269, que tratam dos rumores contra a reputação do Estado e das "associações subversivas"; O uso legítimo das armas previsto no artigo 53 e que ainda é, em parte, vigente e da pena de morte, que foi completamente revogada após o fim do regime de todos os tipos penais às quais se associava. $\mathrm{O}$ apontamento está no fato de que destinava-se majoritariamente à sancionar tipos penais integrantes dos capítulos acima elencados, ou seja, ofensivos à personalidade do Estado.

Como já abordado no tópico inicial do primeiro capítulo, a doutrina ainda não está pacificada quanto o fato de existirem institutos remanescentes do autoritarismo no atual Código penal italiano, uma vez que se trata de uma versão editada e parcialmente revogada, mas não um novo Código. O artigo 265, justamente, é emblemático deste fenômeno. Estando vigente até pouco tempo e cuja proposta de lei de ab-rogação é datada apenas de 2015, o conteúdo de tal dispositivo apresenta de forma bastante clara os delineamentos típicos do caráter autoritário remanescente. Trata-se da previsão do crime de "disfattismo politico", que segundo o texto da referida proposta de lei, "appare emblematico poiché comprende nella propria fattispecie la diffusione sia di notizie false, sia di notizie 'esage-

dell'associazione piuttosto che per la sua pericolosità oggettiva. Andava da sé che il reato associativo fosse tarato su una reazione repressiva forte contro movimenti politici antagonistici al regime fascista". 
rate o tendenziose, che possano destare pubblico allarme o deprimere lo spirito pubblico o altrimenti menomare la resistenza della nazione', annoverando anche attività, quasi per nulla definite, tali 'da recare nocumento agli interessi nazionali","

Não obstante os institutos ab-rogados e retirados, é possível constatar que, resgatando o conceito já explorado por Skinner, uma "mácula" se sobrepõe a essa legislação, uma vez que remanescem alguns institutos de caráter autoritário e a própria estrutura do Código, bastante emblemática em refletir suas prioridades.

\section{Conclusão}

O Código Rocco apresenta como inovação emblemática do momento autoritário vivenciado pelos universos político e jurídico italiano entre as décadas de 1920 e 1930 a elevação da categoria da personalidade do Estado como fundamento para a implementação de suas prioridades ideológicas, em particular de objetivos e ações voltados a legitimar a agressiva política penal do fascismo.

A identificação desse fenômeno, justamente, passou pela localização da função desempenhada pela legislação criminal no regime fascista italiano, utilizando como ponto de referência a importância do papel punitivo segundo as matizes teóricas e políticas do regime autoritário e de acordo com os próprios idealizadores do mesmo, Alfredo Rocco, e de seu irmão, Arturo Rocco. As declarações deste último sobre o tecnicismo jurídico, assim como suas obras jurídicas, foram essenciais para a fundamentação técnica do Código.

Por meio da análise das tensões punitivas adotadas nessa legislação criminal e sua contextualização no processo de consolidação do regime fascista, é possível verificar que a elevação da figura estatal, sujeito de direitos principal daquela ordem, compôs de formar basilar a estrutura autoritária do fascismo. A personificação estatal, que chega a resgatar o conceito do antigo regime de laesa maiestas foi um elemento-chave para a justificação autoritária e imposição de institutos violentos e repressivos 
contra os indivíduos que se enquadrassem em potenciais ofensores do sujeito principal da ordem jurídica.

Essa orientação base pôde ser identificada nas escolhas legislativas do Código Penal, que se destinou à tipificação de condutas potencialmente lesivas à personalidade do Estado, ainda que somente no campo do planejamento mental dos indivíduos. Essas condutas abrangem um rol amplo de ações, cuja previsão viabiliza o controle da esfera cível pelo Estado em níveis até então desconhecidos.

Em muitos ambientes a referida dinâmica reveste-se do manto da neutralidade por meio da adoção do estilo do tecnicismo jurídico para redação do Código, alegadamente destinado a eliminar qualquer traço de subjetividade da lei criminal, no entanto servindo ao propósito de legitimação intelectual e técnica de uma dinâmica punitiva extremamente autoritária.

Nesse azo, identificou-se o papel central que a subjetivação do Estado como categoria central do regime penal tomou na instrumentalização do autoritarismo fascista, dada a legitimação de institutos repressivos que objetivaram sua autodefesa, por meio da imposição de restrições à liberdade e vida dos indivíduos, ora inimigos da ordem estatal.

\section{Referências}

BOVIO, Corso. Delitti e delinquenti nel nuovo codice penale. Guida, Napoli, 1931.

COSTA, Pietro. Lo "Stato totalitario": un campo semantico nella giuspubblicistica italiana. Quaderni Fiorentini per la Storia del Pensiero Giuridico Moderno, v. 28, p. 61 ss., 1999.

DAL RI Jr., Arno. O Estado e seus Inimigos: a repressão política na história do direito penal. Rio de Janeiro: Revan, 2006. 396 p.

DE FRANCO, Emanuele. La repressione penale delle opinioni dal codice Rocco al diritto dell'Unione Europea: Problemi politicocriminali e dogmatici e prospettive di riforma. 2014. Tesi (Dottorato) 
- Università degli Studi di Napoli Federico II. Dipartimento di Giurisprudenza. 2013-2014. Disponível em: http://www.fedoa.unina. it/9704/1/tesi\%20di\%20dottorato\%20completa.pdf. Acesso em: 15 out. 2018.

FERRAJOLI, Luigi. La cultura giuridica nell'Italia del Novecento. Laterza, 1999. $128 \mathrm{p}$.

FIANDACA, G. Il codice Rocco e la continuità istituzionale in materia penale, Dibattito su "Il codice Rocco cinquant'anni dopo", in La questione criminale, 1981.

GARFINKEL, Paul. Criminal Law in Liberal and Fascist Italy. Cambridge: [s.n.], 2017.

GENTILE, Emilio. Fascism and the Italian Road to Totalitarianism. Constellations. 2008. Disponível em: https:/onlinelibrary.wiley.com/doi/ abs/10.1111/j.1467-8675.2008.00492. Acesso em: 19 out. 2018.

GIUFFrIDA, Antonio. Delitti Contro la Personalita' Dello Stato. Issue 1May-June 2014. Disponível em: https://www.nuovefrontierediritto.it/ delitti-contro-la-personalita-dello-stato/. Acesso em: 15 out. 2018.

MARQUES, Tiago Pires. Crime and the Fascist State, 1850-1940. London: Pickering \& Chatto, 2013. 226 p.

MINISTERO DELLA GIUSTIZIA. Dipartimento per gli Affari di Giustizia. I Lavori Preparatori Dei Codici Italiani: una bibliografia. Biblioteca Centrale Giuridica, 2013. Disponível em: https://www. giustizia.it/giustizia/protected/1303127/0/def/ref/BAR951284/. Acesso em: 21 out. 2018.

MINISTERO DELLA GIUSTIZIA E DEGLI AFFARI DI CULTO. Lavori preparatori del codice penale e del codice di procedura penale. Roma: Mantellate, 1930. v. VII.

MUSUMECI, Emilia. Fascism and Criminal Law in Italy: an outline. Artikel vom 13.10.2017. Disponível em: https://forhistiur.de/media/ zeitschrift/Musumeci_-_1-fo_sVtYS4X.pdf. Acesso em 25 out. 2018. 
NUNES, Diego. Processo Legislativo para além do Parlamento em Estados Autoritários: uma análise comparada entre os Códigos Penais Italiano de 1930 e Brasileiro de 1940. Revista Seqüência, Florianópolis, n. 74, p. 153-180, dez. 2016.

ORLANDO, Vittorio Emanuele. Del fondamento giuridico della rappresentanza politica (1895), in Id., Diritto pubblico generale Scritti varii coordinati in Sistema. Milano: Giuffrè, 1940.

PEDREIRA, Mario Bulhões. Codigos penaes modernos [1932]. Revista de Direito Penal, [S.l.], v. I, fasc. I, abril, 1933.

PICK, Daniel. Faces of Degeneration: a European Disorder, C.18481918. Birkbeck College, University of London. 1993.

ROCCO, Alfredo. La trasformazione dello Stato: dallo Stato liberale allo Stato fascista. Roma: La Voce anonima editrice, 1927.

ROCCO, Alfredo. Relazione a sua Maesta `il Re del Ministro Guardasigilli (Rocco) Presentata nell'udienza del 19 Ottobre 1930VIII per l'approvazione del testo definitivo del Codice Penale. Lavori Preparatori del Codice Penale e Del Codice di Procedura Penale, [S.l.], v. VII, Testo del Nuovo Codice Penale con la Relazione a Sua Maesta `il Re del Guardasigilli (Rocco), Ministero della Giustizia e degli Affari di Culto, p. 7-28. Rome: Tipografica delle Mantellate.

ROCCO, Alfredo. Legge sulla disciplina politica dei rapporti collettivi del lavoro, speech delivered before the Senate of the Kingdom on 11st March 1926, in Id., La trasformazione dello Stato. Dallo Stato liberale allo Stato fascista, Roma: La voce anonima editrice 1927.

ROCCO, Arturo. Il problema e il metodo nella scienza del diritto penale. Milan: F: Vallardi. 1910.

ROMANO, M. Il codice Rocco e i lineamenti di una riforma del diritto penale politico, in La questione criminale, 1981. p. 145-168; SBRICCOLI, Mario. Le mani nella pasta e gli occhi al cielo. La penalistica italiana negli anni del fascismo. Quaderni Fiorentini per la Storia del Pensiero Giuridico Moderno, [S.l.], v. 28, p. 817 ss. 1999. 
SBRICCOLI, Mario. Justiça Criminal. Tradução de Ricardo Sontag. Discursos Sediciosos, [S.l.], n. 17-18, 2011.

SERENI, Andrea. Delitti contro la personalità dello Stato. 2012.

Disponível em: http:/www.treccani.it/enciclopedia/delitti-contro-lapersonalita-dello-stato_(Diritto-on-line)/.Acesso em: 25 out. 2018.

SKINNER, Stephen (ed.). Fascism and Criminal Law: History, Theory, Continuity, Edited by Stephen Skinner. Oxford: Hart, 2015.

SKINNER, Stephen. Tainted law? The Italian Penal Code, Fascism and democracy. International Journal of Law in Context, [S.l.], v. 7. p. 423-446, 2011.

SKINNER, Stephen. Violence in Fascist Criminal Law Discourse: War, Repression and Anti-Democracy. International Journal for the Semiotics of Law - Revue internationale de Sémiotique juridique, [S.l.], v. 26, 2013.

SONTAG, Ricardo. Código criminológico? Ciência jurídica e codificação penal no Brasil (1888-1899). 1. ed. Rio de Janeiro: Revan, 2014. v. 1. 368p.

E.R. ZAFFARONI, Alla ricerca del nemico: da Satana al diritto penale cool, in Studi in onore di Giorgio Marinucci, Milano 2006, p. 763.

Arno Dal Ri Jr. é Doutor em Direito pela Università Luigi Bocconi de Milão, com estágio de pós-doutorado pela Université Paris I (Pantéon-Sorbonne). Mestre em Direito pela Università degli studi di Padova. Professor do curso de graduação e do Programa de Pós-Graduação em Direito da Universidade Federal de Santa Catarina.

E-mail: arnodalri@gmail.com

Endereço profissional: Universidade Federal de Santa Catarina - Campus Universitário Trindade, Florianópolis, SC, Brasil. CEP: 88040-900. 
Kristal Moreira Gouveia é Mestranda em Teoria e História do Direito pela Universidade Federal de Santa Catarina. Especialista em Direito Público pela Faculdade Paraíso do Ceará. Professora do curso de graduação em Direito da Faculdade Paraíso do Ceará. Pesquisadora no Grupo de Pesquisa em História da Cultura Jurídica - Ius Commune (UFSC/CNPQ).

E-mail: kristalmoreiragouveia@gmail.com

Endereço profissional: Faculdade Paraíso do Ceará. Rua da Conceição, n. 1.228, Bairro São Miguel, Juazeiro do Norte, CE. CEP: 63010-465. 
